\title{
Structural Correspondence Between Organizational Theories
}

\author{
Herman Aksom ${ }^{1}$ (D) - Svitlana Firsova ${ }^{2}$ \\ Received: 17 July 2020 / Accepted: 6 January 2021/ Published online: 26 January 2021 \\ (C) The Author(s) 2021
}

\begin{abstract}
Organizational research constitutes a differentiated, complex and fragmented field with multiple contradicting and incommensurable theories that make fundamentally different claims about the social and organizational reality. In contrast to natural sciences, the progress in this field can't be attributed to the principle of truthlikeness where theories compete against each other and only best theories survive and prove they are closer to the truth and thus demonstrate scientific knowledge accumulation. We defend the structural realist view on the nature of organizational theories in order to demonstrate that despite the multiplicity of isolated and competing explanations of organization-environment relations these theories are still logically compatible and mutually consistent which, in turn, assures theoretical progress in the field. Although postulating different and incompatible ontologies, three most successful organization-environments theories, namely, contingency theory, new institutionalism and population ecology share the same explanations of the relations between organizations and environments at the structural level. Without this principle one would say that what occurs in the field of organization theory is a change rather than a progress.
\end{abstract}

Keywords Organization theories · Institutional theory · Population ecology · Contingency theory · Philosophy of science $\cdot$ Structural realism $\cdot$ Correspondence principle

\section{Introduction}

Our attitudes toward scientific theories and the logic of their emergence, development and disappearance constitute major questions for the philosophy of science (Popper 1963; Laudan et al. 1986; Psillos 1999; Niiniluoto 1984). Each science and scientific discipline is demanded

Herman Aksom

hermanaksom@univ.net.ua

1 Jyväskylä University School of Business and Economics, P.O.Box 35, 40014 University of Jyväskylä, Jyväskylä, Finland

2 Taras Shevchenko National University of Kyiv, Vasylkivska str., 90A, Kyiv, Ukraine 
to answer under what conditions researchers will accept or abandon theories (Lakatos 1970; Popper 1963) and what makes theories useful and, in fact, scientific (van Fraassen 1980; 1993; Niiniluoto 1984). These questions are derived from an even more fundamental issue - the task of proving that science in general and any scientific field, in particular, is not just irrational enterprise and theory change is not just a kaleidoscope of false assumptions (Laudan 1981, 1984; Niiniluoto 1984, 2015). In organizational research this problem is most evident and stands out prominently given various incommensurable theories and paradigms proliferation (Pfeffer 1993; Donaldson 1995; Scherer and Steinmann 1999; Scherer 2003, Rabetino et al. 2020). This issue concerns the relationships between competing theories, namely, their seemingly incommensurable assumptions about the nature of organizations, environmental demands, their behavior, structure, life cycle and survival prospects (Burrell and Morgan 1979; Willmott 1993; Rolin 2011). Together, different ontological assumptions, empirical generalizations and theoretical claims make these theories, although, highly successful empirically, but mutually inconsistent and logically incompatible. For instance, Van de Ven noted that "instead of building scientific knowledge that better approximates reality, we are building more and more paradigms without a means for reconciling them" (Van De Ven 1999: 119). Given such paradigm fragmentation can we prove that "we are doing science and not some other form of interpretation" (Weick 2016:334) and that cumulative theoretical development is present in organizational research (Davis 2010, 2015)?

Philosophy of science inevitably puts forward the question "how does science progress?" while the subordinate problem is "in what does scientific rationality consist?" (Jarvie 1979:484). In this paper we put these questions in the context of the major issue in organization theory, mainly, the problem of field fragmentation and multiple paradigms proliferation. ${ }^{1}$ The question that emerged at the beginning of the 1990s has been concerned with the increasing number of incommensurable theories and paradigms with little or no communication between each other (Pfeffer 1993; Donaldson 1995). The state of the art of the organization theory allows talking about the lack of progress in the field mainly due to the absence of communication across the paradigms and we don't have a kind of correspondence that, for example, physical theories hold between each other. As such, there are two lines of demarcation: the first one deals with the paradigm incommensurability while another one refers to the disintegration and competition among conflicting theories about organizational behavior and structures. The first one is irrelevant for our discussion since ontological and epistemological issues of this kind do not affect real scientific practice. The second line of the divide, in contrast, considers the use of theories and their logical inconsistency which philosophers of science often frame as "if Einstein is right then Newton is wrong" (Weinert 1994). When considering even the most successful scientific theories such as relativity vs. classical mechanics or quantum theory vs. classical mechanics "these theories are held to embody such fundamentally different ways of describing the world that they are incommensurable or, in other words, that there are no applicable objective standards which can reveal one theory as better than the other... As a result, scientific development, whenever it involves transitions between incommensurable theories, seems to be merely change, and not progress" (Moberg 1979:245). Structural realism mobilized in this paper is needed in order to overcome this problem.

\footnotetext{
${ }^{1}$ We distinguish between two different debates on incommensurability in management and organization studies, namely, between competing theories and competing philosophical assumption. It is the former debate that we studied in this paper.
} 
When justifying organizational research and the trajectory of organizational theories use and development we need to explain the modern dominance of macro organizational theories from the 1970s (Greenwood et al. 2008; Davis 2010; Suddaby et al. 2011) as scientific progress and rational means of pursuing goals. These questions about rationality and progress in organizational research have been raised many times during the last decade (Davis 2010, 2015) and organizational theories are the most suitable level of analysis. Some see a problem in the absence of new theories (Suddaby et al. 2011) and it is natural that the next question is about how rational and useful it is to mobilize those theories crafted for the twentieth century world for the problems we experience in the new millennium. As such, we need to understand the logic of theories' acceptance, maintenance and abandonment (Bunge 1973; Lakatos 1974). While the later is almost absent in organizational research, the logic of acceptance and maintenance can tell whether the field of organizational studies progresses. Moreover, while the leitmotif of the philosophy of science in the twentieth century had been centered around the falsification and abandonment of theories as a sign and a cornerstone of scientific rationality and progress (Grunbaum, 1978; Musgrave 1973), the more fruitful question since then has been why scientists do not abandon a theory even when facts contradict it. Can we find rationality and progress in the absence of rivalry and natural selection between competing theories? The main claim of this paper is that the answer to this question is affirmative.

At the first look, the history of organizational studies is a history of a handful of theories that had not changed since the 1970s. While one can say that this is the evidence of the absence of cumulative growth of knowledge and progressive theory change, another perspective would say that survival of these theories and our inability to develop new theories (Suddaby et al. 2011) only show that these domains of experience are fully covered by these theories which adequately and satisfactorily explain organizational aspects (Aksom et al. 2020). These particular theories reached their natural limit of growth but researchers do not abandon them as useful tools which proved their instrumental utility and usefulness in addressing a range of questions such as organizational structure, behavior, decision-making, boundaries, change, adaptation, design, diversity and similarity (Davis 2010; Aksom et al. 2020). While these theories are useful and in some sense, we accept and maintain them as true (or empirically adequate) descriptions of particular aspects of organizational life, it is important to ask whether all these theories can successfully describe one and the same world given that they all contradict and challenge each other. Besides merely ontological questions, do, for instance, institutional theory and population ecology explain the same organizational world? Isn't it that the laws of nature in this world differ in a fundamental way? Can we claim that contingency theory, population ecology and institutional theory describe just different aspects of the same world?

Scientific theories either survive scientific revolutions or scientists abandon them in favor of new theories which better address and describe the structure and logic of empirical phenomena (Popper 1963; Kuhn 1970; Putnam 1974, 1981). In organization theory there was a major paradigm shift from contingency theory to population ecology, new institutionalism, resource dependency theory and transaction cost economics and few other theories that challenged rational and adaptive conceptualization that contingency theories assign to organizations and individuals. As a result we should answer two questions: 1) given that a contingency theory had not been abandoned, what aspects of this theory proved to be true (empirically adequate) and 2) did new theories retain these aspects in their structure so we could have said that all existing organizational theories describe the same reality? In other words, is there a cumulative shift (Post 1971; Krajewski 1977; Radder 1991; Weinert 1994; Niiniluoto 2015) when new 
theories emerged and challenged the dominant at that time theoretical perspective? How much form and content of the previous theory had been retained in the succeeding theories?

We propose a structural realist view on the field of organizational research and argue that there is a cumulative growth in organization theory development and structural correspondence between existing organization-environment theories. We limit our analysis to population ecology and new institutionalism in order to show how these two succeeding theories share the common ground with their predecessor - contingency theory. There is a cumulative shift between contingency theory and its successors - institutional theory and population ecology and, furthermore, institutional and population approaches do shares the same structural basis. There are concepts such as organization-environment relations, conformity, adaptation and isomorphism that had been retained through the paradigms shift and key elements of contingency theory survived the 1977 revolution.

\section{The Nature and the Role of Scientific Theories and the Absence of New Theories in OMT Research}

Questions such as "is it rational to build theories and use them in explanation and prediction?", "why should we trust, believe and accept theories?" and "whether new and alternative theories contribute to the growth of knowledge and scientific progress?" are possible and reasonable due to the very nature of scientific theories and their relation to observation and raw data. Theories claim the existence of unobservables. By postulating and claiming the existence of some unobservable phenomena and going beyond any direct empirical check (Worrall 1982), scientific theories invite debates about the possibility of trusting something that speculates about unobservables but nevertheless they perform as tools that allow us to categorize data, recognize patterns and causal relationships, explain and predict phenomena in a particular domain of experience ${ }^{23}{ }^{4}$ Hooker defined a scientific theory in the following way:

"Successful sufficiently fundamental theories not only fit and unify their data fields but also prescribe the general terms in which relevantly to describe observation; specify what is and is not observable; specify the conditions under which what is observable, is observable; specify the instrumental means and reliability by which what is measurable is measured; specify what is causally, statistically, and merely accidentally connected" (1975:152).

Theory building is an intelligent guesswork (Popper 1963; Lesher 1978; Hooker 1975). It is by no means a direct induction from facts to generalizations since theories are more than data

\footnotetext{
${ }^{2}$ Another interesting example of different, incompatible ontologies comes from organizational theories of diffusion. Competing theories postulate alternative ontologies in order to describe the nature and processes of ideas circulation and adoption by organizations. As such, their flow has been conceptualized as diffusion and translation (or traveling) while the very nature of management concepts and ideas has been understood as technical advances, cultural myths, fads, fashions and, more recently, viruses (Røvik 2011; Madsen and Slåtten 2015).

${ }^{3}$ From the point of view of scientific realism, Psillos (1999) lists a number of virtues and demands that scientific theories must meet. In particular, theories should be coherent with other established theories, be completed, avoid ad hoc hypotheses, contributing to unification and generate novel predictions. A key claim from realists' camp here is that theories must be more than empirically adequate.

${ }^{4}$ Another important virtue of many successful theories is their logical coherence and the absence of any arbitrary hypotheses (Mamchur 1987; Engler 2002).
} 
accumulation and classification (Bunge 1973). ${ }^{5}$ It is a task of recognizing previously unnoted connections and patterns that cannot be directly derived from facts and observations, finding hidden, nonobvious and unrecognized relations and patterns (Ayala 1968). ${ }^{6}$ Without pure thinking and counterintuitive reasoning (Bunge 1973; Aksom and Tymchenko 2020; Sandberg and Alvesson 2020), a simple mechanical induction based on observations cannot generate a theoretical generalization and understanding of the nature of phenomena (Bunge 1973). One of the founding figures in American sociology - Albion Small, noted that we come to know and understand any phenomena only when systematic theory building replaces observations and experience:

"We have society... it is perfectly familiar. Why study it? People have asked the same question about all familiar things when it was first proposed to study them, and build up scientific knowledge about them. People had breathed air, for example, thousands of years before it occurred to anybody to study air. When scholars began to talk about studying air ordinary people laughed at them. "The idea of studying air! Why not study something worth while? Everybody knows all about air." It proved, however, that nobody really knew much of anything precisely about air. People did not so much as know that air is heavy, that it is elastic, that it is a mixture of gases, etc." (Small 1897:147). ${ }^{7}$

A gap between direct observations and theoretical propositions is filled in with guesses which create a space for different interpretations for philosophers of science with regard to our attitudes towards theories. A key feature of scientific theories is their claims about the existence of unobservable phenomena and relations between observables and unobservables (Worrall 1982; Achinstein 2000, 2002; Psillos 2011; Mamchur 2017; Ladyman 2018; Cao 2019). Scientists deduce claims about the existence of unobservables but we cannot be sure about whether these phenomena really exist and whether scientists provided their correct description (Worrall 1982; Godfrey and Hill 1995; Mamchur 2017). Nevertheless, whether successful theories correctly describe the nature of hidden reality, their empirical adequacy allows explaining and predicting observable phenomena.

Scientific theories are used in two ways. In the first case (and this is the dominant mode in management and organizational research) we chose a particular theoretical framework in order to make sense of and explain empirical findings as we deduce conclusions from the general claims a theory holds. In the second mode, we try to find out whether a particular theory is worth using in scientific inquiry and we try to test a theory via empirical data or experiment in

\footnotetext{
${ }^{5}$ Reflecting on the primary role of imagination and guesswork in theory building Freeman Dyson noted that "General relativity is the prime example of a physical theory built on a mathematical "leap in the dark." It might have remained undiscovered for a century if a man with Einstein's peculiar imagination had not lived" (1965:131). According to Einstein himself, general relativity is such a nontrivial theory that its creation could have been postponed for 50 years (Dyson 1964). It is remarkable that it was in the 1960s that works began to appear leading to general relativity in a regular way, without that ingenious insights, expressed by Einstein at the beginning of the century (Zel'dovich 1977).

6 "It is the concern of science to formulate theories, that is, to discover patterns of relations among vast kinds of phenomena in such a way that a small number of principles can explain a large number of propositions concerning these phenomena. In fact, science develops by discovering new relationships which show that observational statements and theories that had hitherto appeared as independent are in fact connected and can be integrated into a more comprehensive theory" (Ayala 1968:207).

${ }^{7}$ The same is definitely true for organization theory as well (Scott 1981). Moreover, as, for example, Perrow claims, organizational research has a primacy over the study of society since "organizations have absorbed and vacuumed up much of society" (Perrow 1991:726).
} 
a hope of understanding when a theory should be taken seriously and when a theory should be rejected. In contrast to realism/antirealism debate regarding the nature of scientific theories and their ability to uncover the truth, the question about the scientific utility of our theories is more about the practical matter rather than philosophical. When talking about the reasons for accepting, maintaining and rejecting theories we are talking about the practical needs of researchers and their ability to use theories as tools for the job (Suddaby, 2010; Aksom et al. 2020; Aksom and Tymchenko 2020). It is therefore crucial to understand the logic of theory acceptance and rejection as well as the history of these procedures in organizational research.

The most typical mode of theory use in management and organizational studies relates to the confirming instances of theories and these cases are two-way traffics where researchers both verify a theory and explain their findings within this theory (or, alternatively or supplementary, they also legitimate their findings within highly accepted theoretical framework).

1. Theories are used for explaining empirical findings;

2. Theories face empirical tests in order to verify, corroborate or reject them;

3. Theories are modified artificially and ad-hoc in order to fit the findings.

"The surviving theory is the best theory" (Popper 1959:419) and in our case we can suggest that the list of macro theories of organizations remains unchanged simply because these theories survived, that is, hasn't yet been found false. They have survived given their ability to explain a set of phenomena and they are useful in the limited domain of their applicability. No doubt, it is an overly ambitious expectation to demand new organizational theories just because we need something new for the sake of novelty (Hambrick 2007;). New theories emerge either in response to some perceived empirical anomaly and problem (Feyerabend 2010; Laudan et al. 1986; Cevolani and Tambolo 2013; Aksom 2020) or when a new area of experience is discovered (Heisenberg 1987). Scientists do not invent new theories just because they are bored (Einstein 1934), but because they have to develop an appropriate tool for the new domain of science. For example, quantum mechanics emerged in response to physicists' inability to explain atomic processes. Different domains of science required fundamentally new theories for those areas of nature where classical physics had been silent about. As a result, new theories replace old theories which, in turn, are either abandoned altogether or saved as an approximation and a special case of new and broader theory.

What conclusions can be drawn from the fact that we don't have new theories since the 1970s? We have enough theoretical equipment for addressing traditional research questions and organizational domains and new theories can't arise simply because we have not yet discovered fundamentally new domains of organizational reality. But the current problem lies in the perceived ontological incommensurability between these theories. Worrall described the problem that often arises when different theories coexist and demonstrate empirical adequacy and validity in their respected domain:

"Newton's theory of gravitation had a stunning range of predictive success... Unfortunately Einstein's theory is not simply an extension of Newton's. The two theories are logically inconsistent: if Einstein's theory is true, then Newton's has to be false" (Worrall 1989).

This implies that we have no logical reasons to accept either of available theories as true because either one of them is false or all theories are equally wrong and it can be expected that 
they will be replaced in the future with new false theories. But the minimal argument that follows from the fact of the coexistence of competing theories is that these theories "are incompatible and therefore implies that no correspondence relations obtain between these two theories" (Weinert 1994:304).

\section{Incommensurability, Scientific Progress, Correspondence Principle and Structural Realism}

Niiniluoto (1984, 2015) warns against confusing progress with change maintaining that progress should be distinguished from such neutral descriptive terms as "change" and "development". ${ }^{8}$ Change does not ensure progress; in a scientific field ontological commitments may change each other but this field does not necessarily progress by simply replacing postulates about unobservable entities. This position reflects the view of Thomas Kuhn on the nature of scientific change as a non-cumulative discontinuous paradigm shift. According to antirealists, there is no place for the accumulation of our objective knowledge when one false theory is replaced with another false theory and different paradigms simply change each other. Instead, it is legitimate to talk about scientific progress when a scientific field qualitatively advances, improves and accumulates knowledge and understanding over time. Bird (2007) argues that scientific progress consists in increasing knowledge and Dellsén (2016) maintains instead that progress should be understood as an increase in understanding (Park 2017). Instrumentalist's answer is an increase in effectiveness for solving scientific problems (empirical adequacy). The impossibility of direct empirical verifications and head-to-head competition motivates other approaches that simply an increase in truthlikeness.

Philosophers and historians of science consider the correspondence principle as a requirement for theories to describe the same reality and conform to the same ontology and logic of causal-relations (Weinert 1994; Aksom et al. 2020; Firsova et al. 2020). Correspondence among other theoretical and analytical functions serves the purpose of addressing Kuhn's minority view: revolutionary changes between theories, in particular between Newtonian and Einsteinian mechanics, "implied the rejection of one in favour of the other" (Weinert 1994:306; Böhme 1980). It becomes even more difficult to account for scientific progress given that incommensurability thesis must be somehow aligned with the empirical success that different contradicting theories demonstrate and their certain claims to reality despite different ontological assumptions (Rohrlich 1988:296). Böhme puts the concept of closed theories in the context of scientific revolutions, incommensurability and progress noting that "some theories reveal a stability that far exceeds that which Kuhn has demonstrated: they even survive scientific revolutions": in this case we talk about the closed theories that invite no revisions as they are completed and exhaustive descriptions of a certain domain of reality. The concept of closed theories offered by Heisenberg can be regarded as an instrumentalist position as we talk about practical utility instead of true value. Less radical perspective sticks to the view that there is a correspondence between different theories even when old theories do not survive (Firsova et al. 2020). In this case, a new theory is a rational generalization of an old one while both depart as little as possible from each other (Bokulich and Bokulich 2005:347). Due to the correspondence between successor and predecessor theories one can claim that scientific

\footnotetext{
8 "Progress" is a normative or goal-relative rather than purely descriptive term: saying that the step from one theory A to another theory B constitutes progress means that B is an improvement of $A$ in some respect" (Niiniluoto (1984:75-76).
} 
progress occurs even during scientific revolutions and this move allows overcoming Kuhn's incommensurability thesis to some degree.

Unification is often mentioned as another sign of scientific progress (Kapp 1958; Freedman and Van Nieuwenhuizen 1978; Smolin 2006; Nugayev 1985, 2015). Following Niiniluoto, unification is a goal-directed expression of scientific progress: a development towards simplicity and unity allows pursuing the main aim in most sciences - "to discover in the diversity of forces a simpler underlying order" (Freedman and Van Nieuwenhuizen 1978:126; Post 1960). In the context of this study, we consider structural correspondence as a special case of unification. Structural realism, turn, abandons metaphysical claims, maintaining that all we can know is the structural relations that theories describe and these relations are those aspects that survive during revolutions and bridge different theories (French and Ladyman, 2003; Cao 2003). Here, scientific theories may offer different, conflicting theoretical terms (Achinstein 1963) but maintain the same structural features of the world. A correspondence of structure between our theories and the world is enough to explain their empirical success.

\section{The Role of Falsification and Theory Testing}

A minimal requirement for scientific theory assumes its ability to be in agreement with observations (experiments). Ellis and Silk (2014) claimed that abandoning empirical verifications is nothing but a violation of the scientific method. They argue against the view that "if $a$ theory is sufficiently elegant and explanatory, it need not be tested experimentally, breaking with centuries of philosophical tradition of defining scientific knowledge as empirical" (2014:321). At the same time, in modern physics (and especially in cosmology) there are precedents of theory maintenance even with no empirical evidence at all (Dawid 2013, 2019). Additionally, "much of the forefront of theoretical physics deals with situations so extreme that there is no hope to probe them experimentally" (Thorne 1991:182). These extreme and nonrefuting instances include even such paradoxical and exotic mathematical deductions from General Relativity as the possibility of traveling back in time as Kurt Gödel (1949) showed (a kind of prediction that obviously cannot be verified at this stage of scientific and technological development). It is this main criterion of being scientific in nature that Popper (1963) put forward: a requirement that a theory which is not refutable by any conceivable event is nonscientific.

When Davis (2010) writes about scientific progress and its absence in organizational research he refers to Popper's notion of science as a method of conjectures and refutations (Maxwell 1972; Cevolani and Tambolo 2013, Tambolo 2015; Papineau 1996). ${ }^{9}$ Karl Popper showed that all inductive inferences are unjustified so do any verifications of theories and hypotheses. But there is an asymmetry between verification and falsification: a theory can never be said to be confirmed and acknowledged as true but it can't be shown false as well. It can contradict empirical evidence, being salient about some new phenomena or fail with predictions and still scientists maintain these theories.

Popper's falsification criterion faces numerous objections and counterarguments. Falsificationism can't tell when theory is true and it can't recognize the truth (Maher 1990).

\footnotetext{
${ }^{9}$ In fact, Popper's philosophy of scientific progress doesn't fit realities of organization theory along two dimensions. First, there are no refutation and theory selection. Second, given the variety of different theories that account for the same phenomena, it is more safe to assume that empirical adequacy rather than truthlikeness plays a defining role in researchers' acceptance of organizational theories.
} 
As a result, it is impossible to be sure whether a true theory hasn't been refuted and a false theory has been corroborated. Duhem-Quinne thesis claims that it is impossible to test a hypothesis in isolation. Miller and Tichy proved that we cannot add true components of a theory without increasing also the corpus of false claims (Niiniluoto 1987; 2019). Most philosophers of science think falsificationism is fatally flawed. Given the above mentioned objections, it is reasonable to agree that falsifiability can't serve as a means for identifying theories as false and rejecting them. However, falsificationism should play even more important role. First, beyond doubt, it allows us ensuring that those hypotheses and theories that are in principle falsifiable are scientific. This is a central thesis in Popper's philosophy of science but this "function" of falsifiability is not the only virtue of good scientific theories.

Together with Lakatos and Musgrave, Böhme maintained that "scientists actually do not follow the methodology of falsificationism; rather, they stick to theories even in cases where anomalies are at hand" (1980:163). What they do, however, and what falsificationism allows for is recognition of new areas of experience and respectively recognition of the boundaries of existing theories. It is the major virtue of the falsifiability principle is that we can say where the old domain of a scientific field of theory ends up and where the new domain begins (Heisenberg 1987; Bokulich and Bokulich 2005; Aksom et al. 2020; Firsova et al. 2020). Respectively, we can understand which problem and area of experience a new theory should address, explain and predict. This virtue of falsifiability allows simultaneously explain how closed theories can exist without contradicting Popper's verisimilitude notion of progress and Bohr's correspondence principle (Weinert 1994).

In the next section we will consider another shortcoming with the falsificationism and propose another conceptual framework for defending the cumulative and progressive nature of organizational research.

\section{The Absence of New Theories and Theory Change}

As Lakatos, Laudan, Musgrave, Bunge, Papineu, Weinberg, Bohme and many other scientists and philosophers of science noted, rarely researchers follow the falsification principle and instead use to maintain problematic theories even in the light of contradicting evidence or anomalies. Moreover, some theories even survive the scientific revolutions (Bohme, 1980). Nevertheless, new theories emerge either as substitutions for their predecessors or to coexist and become another tool for a job. Whether there is an abandonment of theories or not, the question is whether there is a correspondence and cumulative shift between theories? As we have said, it is rare and unlikely that theories abandoned and discarded in the course of scientific development. More often an old theory becomes a limiting case of the superseding theory and this new theory simply limits the domain of the applicability of the old theory (Weinert 1994:304).

Davis $(2010,2015)$ questions the presence of progress in organizational research given that there are no head-to-head competition among different theories and no experience of falsifying and discarding unsatisfactory and false theories. Similar to Popper he reasonably expects that the growth of scientific knowledge should take the form of the "repeated overthrow of scientific theories and their replacement by better ones - rather than the accumulation of observations or of data" (1962:285). When we can never be sure that a specific number of verifications would confirm theories, the most suitable indicator of the scientific progress in the field is the dynamics of theory change (Kitcher 1978). Falsified theories are discarded while new theories are closer to the truth and/or better represent reality (Popper 1963; Wray 
2019). The method "of bold conjectures and refutations is held to be THE method of science, because of its purported conduciveness to theories of greater verisimilitude" (Grunbaum, 1976:213). The concept and the notion of progress that Davis might share with Popper and many other philosophers of science is a concept of truthlikeness or verisimilitude:

"such theory-changes as the transition from Newton's to Einstein's theory are progressive because, although the new theory is, strictly speaking, presumably false, it is estimated to be closer to the truth than the superseded one: increasing verisimilitude, or decreasing distance from the truth, is the key ingredient for progress" (2013:922).

Science aims "to have theories which are as close to the truth as possible" (Maher 1990:103) and falsificationism assures this progressive nature of scientific inquiry. In this respect, the question that arises is how progress is possible when no head-to-head competition and natural selection between theories happens?

Moreover, there must be a referential continuity in theory change (Radder 1991; Bokulich and Bokulich 2005). Structural correspondence principle between the predecessor and successor theories demands the latter to be able to explain the success of past theories. The interplay between falsificationism and correspondence principle implies them to be two sides of the same coin: new theory (if successful) is getting closer to the truth (or shows some other sort of advancement) but at the same time, it should hold the predecessor valid theory as a limited case (Bohr) or include in itself the correct aspects of previous wrong theory (Poincare).

Summing up the following concepts of scientific progress and rationality that stems from the falsification principle, we demand theories to compete against each other, being in principle falsifiable and able to be refuted while the progress consists in getting closer to the truth through theories refutation (Popper 1962).

The question that Davis implied is whether we can say that management and organizational research is progressive and what are the criteria and proofs of this progress given the absence of natural selection and refutation of theories? Moreover, even another aspect of Popperian scientific progress, namely, the emergence and development of new theories is absent (Suddaby et al., 2010; Hassard et al., 2013). Donaldson, for example, clearly sees the nature of progress in organizational research as "the overturning of pre-existing theories by falsifying them" (2005:1075).

At the same time, there are various competing views and conceptualizations of scientific progress which falsificationism and verisimilitude concepts directly contradict (Musgrave 1973; Lakatos 1970). These conflicting views leave the door open for other conceptions of scientific progress that fit the field of organizational research. First of all, although Popper found his middle ground between realism and instrumentalism, his conception nevertheless perceived problems with a justification of the notion of truth and getting closer to the truth with each new theory. Even when leaving the problem with falsificationism aside, there are many historical counterexamples to Popper's framework. While Popper's truthlikeness concept had been handled by scientific realists, antirealists question the very possibility of getting closer to the truth. If the history of science is a history of refuted theories we can't deny that many successful theories of the past had been found false and not even approximately true (Laudan 1981, 1984; Niiniluoto 2020). In these cases, no convergence towards the truth can be assigned. This is a question reasonably asked by antirealists: given that past theories had been found completely false and non-referring why should not we expect that present and future theories would be any different? Popper's position is itself a compromise between realism and instrumentalism which aims at defending the progressive nature of science as a kaleidoscope 
of conjectures and refutations. Realists claim that "the success of science would be miraculous if scientific theories were not at least approximately true descriptions of the world" (Ladyman 1998:412) and their central argument faces antirealists' Pessimistic Induction:

"Many theories, such as the ether theories of the 19th century, enjoyed substantial empirical success, despite the fact that to the best of our knowledge, they are false. Indeed, in some cases, wholly false - not even approximately true-because the unobservable entities they posited (e.g., the luminiferous ether) are not just mischaracterized, but do not exist. If false theories can be empirically successful, then the realist's truthbased explanation of success is a non-starter and the explanationist defense of realism comes unglued. Furthermore, if past successful theories are false, it is likely that currently successful theories are false; indeed wholly false-not even approximately true- because in all probability the entities to which they refer do not exist, just as in the past cases. This 'pessimistic induction' from past cases of successful-but-false theories to the status of current theory, bodes ill for explanationist realism. It undermines not just the realists' view that currently successful theories are approximately true, but their view that the greater success of current theories shows that they are more truth-like than their less successful predecessors" (Doppelt 2005:1077).

While, as we argued in the previous section, falsificationism allows for understanding and approaching the boundaries of existing theories, it fails to provide the blueprint for scientific progress defense as the Pessimistic Induction itself refutes the verisimilitude notion.

At the same time, Popper's principles do not account for 1) positive knowledge and 2) nonempirical arguments to trust theories (Dawid 2013, 2019; Rovanelli, 2019). That is, while the concept of falsifiability marks the boundaries of the scientific field it doesn't explain why and how science works:

"Popper points out that a single counter-example can show us that a scientific theory is wrong. But he says nothing about what can show us that a scientific theory is right. Yet it is positive knowledge of this latter kind that makes science important. We can cure diseases and send people to the moon because we know that certain causes do always have certain results, not because we know that they do not" (Papineu, 2002:289).

As such, successful technologies and practical applications are beyond the scope of Popper's explanation. Another problem is that scientists often accept and believe in theories without any empirical support (String theory is the most obvious example). Organizational theories cannot be falsified, they do not applicable for practical applications and they are supported without clear positive evidence. What else then remains in evidence of scientific progress and not merely of change? We will argue that structural correspondence is a virtue that indicates the presence of progress even in the context where empirical tests and practical applications are absent.

\section{Epistemic Pessimism, Structural Realism and the Correspondence Principle}

Scientific realism in its most general form claims the existence of unobservable entities that most successful theories postulate (Achinstein 2002; Ladyman 1998, 2018; Jones 1991) and maintains that the picture science gives us of the world is true (Van Fraassen 1977:623) (see 
Table 1 for basic differences and similarities between scientific realism, antirealism and structural realism). Most scientists claim to be realists (Rohrlich 1996; Weinberg 1994) and "most of us would like to be realists" (Jones 1991:185) since realism is the most intuitively obvious philosophy which accepts that scientific theories describe the world the way it actually is. The most typical argument in favor of scientific realism is the so-called No Miracle Argument which considers the truth of empirically successful theories as the best and the only plausible explanation for their success, concluding that it would be a miracle if they were not even approximately true (Laudan 1981; Park 2011; Wray 2015). Wray reconstructs realists' argument in the following way:

"Realists take the success of our current best theories to be evidence that our theories are true. More precisely, realists take the success of our current best theories as evidence that the claims these theories make about unobservable entities and processes are true or approximately true. Indeed, realists often suggest that the truth or approximate truth of our current best theories is the best explanation of their success" (Wray 2013:1719-1720).

More specifically, scientific realists claim that the aim of science is "to give us a literally true story of what the world is like [ontological thesis] and the proper form of acceptance of a theory is to believe that it is true [epistemological thesis]" (Van Fraassen 1977:623). Few years later van Fraassen developed this thesis into his philosophy of constructive empiricism which, together with structural realism and pessimistic induction is a kind of epistemic pessimism (from the point of view of realists, of course). All three lines of attack on realism

Table 1 Basic similarities and differences between scientific realism, antirealism and structural realism

\begin{tabular}{|c|c|c|c|c|}
\hline & progress & New theory & $\begin{array}{l}\text { Coexisting of several } \\
\text { theories }\end{array}$ & Scientific revolution \\
\hline $\begin{array}{l}\text { Scientific } \\
\text { realism } \\
\text { (no } \\
\text { miracle } \\
\text { argu- } \\
\text { ment) }\end{array}$ & $\begin{array}{l}\text { Scientific theories are } \\
\text { on the right track } \\
\text { and a predictive } \\
\text { power of theories is } \\
\text { a sign of their truth }\end{array}$ & $\begin{array}{l}\text { each new theory is } \\
\text { closer to the truth }\end{array}$ & $\begin{array}{l}\text { SR seems to be silent } \\
\text { about this situation } \\
\text { since it has to argue } \\
\text { that each empirically } \\
\text { successful theory } \\
\text { correctly describes } \\
\text { the nature of reality }\end{array}$ & $\begin{array}{l}\text { Those theories that } \\
\text { survive scientific } \\
\text { revolutions are } \\
\text { closer to the truth } \\
\text { than their } \\
\text { predecessors }\end{array}$ \\
\hline $\begin{array}{l}\text { Scientific } \\
\text { antireal- } \\
\text { ism }\end{array}$ & $\begin{array}{l}\text { Progress either can't be } \\
\text { justified or is } \\
\text { conceptualized in } \\
\text { terms of empirical } \\
\text { adequacy, problem } \\
\text { solving and saving } \\
\text { phenomena }\end{array}$ & $\begin{array}{l}\text { New theory is accepted } \\
\text { as empirically } \\
\text { adequate but we } \\
\text { should not accept it } \\
\text { as true since it will } \\
\text { be completely } \\
\text { abandoned by its } \\
\text { successor }\end{array}$ & $\begin{array}{l}\text { Theories describe } \\
\text { different domains of } \\
\text { experience and } \\
\text { should be nothing } \\
\text { but empirically } \\
\text { adequate } \\
\text { descriptions of } \\
\text { observable } \\
\text { phenomena }\end{array}$ & $\begin{array}{l}\text { New theories emerge } \\
\text { but should be by } \\
\text { default considered } \\
\text { as false and } \\
\text { candidates for future } \\
\text { abandonment }\end{array}$ \\
\hline $\begin{array}{r}\text { Structural } \\
\text { realism }\end{array}$ & $\begin{array}{l}\text { Progress is in } \\
\text { cumulative shift }\end{array}$ & $\begin{array}{l}\text { New theory retains } \\
\text { structural } \\
\text { correspondence } \\
\text { with its predecessor }\end{array}$ & $\begin{array}{l}\text { All theories in fact } \\
\text { should describe and } \\
\text { explain the same } \\
\text { reality and being } \\
\text { about different } \\
\text { aspects of the same } \\
\text { world }\end{array}$ & $\begin{array}{l}\text { Cumulative shift at the } \\
\text { structural level } \\
\text { ensures the } \\
\text { structural continuity } \\
\text { between subsequent } \\
\text { theories across } \\
\text { theory change }\end{array}$ \\
\hline
\end{tabular}


deny the possibility of knowing and discovering the truth picture of the world and reject this virtue of scientific theories. Specifically, van Fraassen aimed at defending the aim of science and the limits of our knowledge "without inflationary metaphysics" (van Fraassen 1980:73):

"By taking a theory to be empirically adequate, the constructive empiricist is simply saying that the phenomena we observe (and believe to exist) can exist within the structure the theory describes, without additionally being committed to saying that the unobservable parts of that theoretical structure are parts of the actual structure of the world" (Monton and Mohler 2012:I).

That is, in contrast to realists who mobilize the notion of truth and accept that mature successful theories are capable of being true and thus being correct about the unobservable entities they postulate (Musgrave 1988; Psillos 1999; Chakravartty 2007), constructive empiricism is an instrumentalist view which considers theories as nothing but useful tool for classifying, explaining and predicting observable phenomena, that is, "saving the phenomena" (Van Fraassen 1977; Bogen and Woodward 1988; Bogen 2011; Massimi 2007). As a result, "science aims to give us theories which are empirically adequate, and acceptance of a theory involves as belief only that it is empirically adequate" (van Fraassen 1980:12). ${ }^{10}$ And while constructive empiricism rejects the notion of truth and substitutes it with the concept of empirical adequacy, structural realism reduces the possibility of truth attaining to the structure and relations between phenomena.

Structural realism as formulated by Worrall in his Worrall 1989 paper acknowledges the argument put forward by the Pessimistic Induction but simultaneously saves the naïve realist view on progress by arguing that there is a cumulative shift between most scientific theories. Structural realism doesn't deny the history of false theories but doesn't break the link between them and the truthlikeness by introducing the notion of structural correspondence. Worrall used the case of the transition in nineteenth-century optics (from Fresnel's elastic solid ether theory to Maxwell's electromagnetic field theory) to demonstrate that there is a cumulative shift and structural correspondence between theories without necessarily taking a realist position:

"There was an important element of continuity in the shift from Fresnel to Maxwell - and this was much more than a simple question of carrying over the successful empirical content into the new theory. At the same time it was rather less than a carrying over of the full theoretical content or full theoretical mechanisms (even in "approximate" form). And what was carried over can be captured without making the very far-fetched assumption...that Fresnel's theory was "really" about the electromagnetic field all along. There was continuity or accumulation in the shift, but the continuity is one of form or structure, not of content...Roughly speaking, it seems right to say that Fresnel completely misidentified the nature of light, but nonetheless it is no miracle that his theory enjoyed the empirical predictive success that it did; it is no miracle because Fresnel's theory, as science later saw it, attributed to light the right structure" (Worrall 1989:117).

As such, structural realism accomplishes at least two tasks:

\footnotetext{
${ }^{10}$ In this sense, empiricism adopts the same perspective as engineering and technology studies do. What matters for technical utility is usefulness and effectiveness regardless of what is the nature of the exploited effect.
} 
1) Explains how very different theories can coexist and logically describe the same world (Bokulich and Bokulich 2005; de Ronde 2018);

2) Explains the theoretical success of rejected theories (Saatsi 2005).

Structural realism puts forward two claims, pessimistic and optimistic ones (Psillos 2001, 2006). The pessimistic thesis reflects the pessimistic induction and by rejecting the possibility of knowing the true nature of the world claims that all that we can know is the structure of the world (Worrall 1989; Ladyman 1998). The optimistic thesis defends the view that there is still a correspondence between past, present and future theories in terms of knowledge retention through the scientific revolution (vertical correspondence) and between each other by sharing and agreeing upon the same reality (Worrall 1989; Rohrlich 1989, 1990, 1996; Ladyman 1998; Psillos 1999). Following Kuhn's incommensurability thesis, many philosophers of science and organizational theorists accept the pessimistic induction's denial of the possibility of progress:

"in fact, some philosophers of science have concluded that as one theory replaces another, science is not cumulative; the old theory is simply wrong while the new one is right - until it is replaced by yet another one" (Rohrlich 1989:1152).

Instead, structural realism can answer why superseded theories had been maintained and it saves the notion and possibility of progress in science by concluding that "scientific theories do not give us knowledge of the intristic natures of unobservables" but "involve[s] commitment to the claim that science is progressive and cumulative and that the growth in our structural knowledge of the world goes beyond knowledge of empirical regularities" (Ladyman 2011:97).

Without the structural correspondence thesis offered by structural realism any discussions on the possibility of scientific progress in any field are precluded. Ontological overload in scientific realism prevents from realizing and accepting the middle ground that structuralists put forward, rejecting, in turn, the possibility of knowing the truth.

While constructive empiricism is an epistemological thesis, structural realism makes ontological claims, focusing not on how to accept/believe scientific theories and on the notion of truth but on what there is in the world and how this world can be depicted in logical, noncontradicting terms. ${ }^{11}$ The common point of intersection between these two positions is their rejection of the possibility of truth claims about unobservables and this position can be traced back to Mach and Duhem who, following Kantian view (that this kind of knowledge is metaphysical because it goes far beyond experience) regarded theories as nothing but conjectures which function is to be useful tools for explanation and prediction (Brush 1968). In particular, Mach maintained that one has no reason to believe in the existence of atoms even though atomic theory could explain and predict a wide range of phenomena. From the scientists' camp Max Planck responded in the following way:

"Whoever rejects faith in the reality of atoms and electrons, or the electromagnetic nature of light-waves, or the identity of heat and motion, can never be found guilty of a logical or empirical contradiction, but he will find it difficult from his standpoint to advance physical knowledge" (Planck in Brush 1968:193).

\footnotetext{
${ }^{11}$ Van Fraassen, Laudan and Musgrave summarized this position as a thesis that "theories need not be true to be good" meaning that constructing true theories is neither the aim nor the ability of science.
} 
Structural realism introduced and solved another problem in a way that leads us to take rather Mach's and Duhem's side (Rohrlich 1988). Scientific realist's success-to-truth inference implies that without assuming that science describes the real world the predictive success of science would be an utter miracle (Carrier 1991:23; Chakravartty 2003, 2004) but both constructive empiricists and structural realists are skeptical and pessimistic with regard to theoretical ability to discover the real nature of unobservable objects, entities and forces. Nevertheless, structural realism maintains that scientists develop the picture of the world which increasingly becomes more and more accurate, even though these theories accomplish this task by discovering the structural feature of the world, not the nature:

"Theories talk about all sorts of entities and processes with which we are not acquainted...we can know about them by description, that is we can know about them via their structural properties" (Ladyman 1998).

We argue that this structural correspondence is also present between existing organizational theories, thus, we defend the view that the shift from contingency theory towards institutional theory and population ecology has maintained basis assumptions and structures of contingency theory. While these theories postulate multiple incompatible ontological claims about the nature of organizations, environments and forces that shape their relations, one thing that remains reliable and stable is the structural correspondence between organizational theories, that is, the way they describe the relations.

\section{Organizational Theories and Scientific Progress}

The theoretical program initiated and pursued by James March and his coauthors in the 1950s-1960s ensured a major reorientation in management and organization studies (March and Simon 1958; Scott 1981; Levinthal and Marengo 2020). Their research and theoretical ideas of bounded rationality, task uncertainty, ambiguity, routines in behavior and environmental impact made a quantum leap over existing paradigm of scientific management and the human relations school. In contrast to classical management theories, the behavioral, open-systems approach to organizational research abandoned pragmatism and applied nature and instead declared organization theory as a legitimate field of scientific study with strong theoretical basis. March and Simon's research program thus paved the way for future theories organization-environment relations (Scott 1981; Davis and Powell 1992). During the 1960s-1980s the field of organization theory had emerged and developed into a fragmented science with multiple, competing and incommensurable paradigms (Scott 1981; Donaldson 1995; Hirsch and Lounsbury 1997; Greenwood et al. 2008; Davis 2010). During the 1960s-1970s a number of competing scientific theories finally replaced the dominant perspectives on scientific management and social organization contributing to the emergence of organizational sociology as a distinctive field of research (Greenwood et al. 2008; Dobbin and Schoonhoven 2010). After a brief review of the history of organization-environment theories proliferation we will discuss the common points of intersections among contingency theory, population ecology and new institutionalism that make it possible to talk about the cumulative growth of knowledge in the field of organization theory (Table 2 summarizes common points and divergence between these theories). 
Table 2 Common points in theories: environmental determinism and response to environmental changes

\begin{tabular}{|c|c|c|c|}
\hline & Contingency theory & Population Ecology & Institutional theory \\
\hline response & Internal adaptation & $\begin{array}{l}\text { Adaptation at the population } \\
\text { level }\end{array}$ & Internal adaptation \\
\hline outcome & Fit (optimal performance) & $\begin{array}{l}\text { Limited possibility to adapt } \\
\text { (organizational survival or } \\
\text { death) }\end{array}$ & $\begin{array}{l}\text { Conformity (survival, } \\
\text { performance } \\
\text { improvement) }\end{array}$ \\
\hline Force & $\begin{array}{l}\text { Technical requirements and } \\
\text { contingency change that } \\
\text { causes misfit }\end{array}$ & selection & $\begin{array}{l}\text { Institutional demands for } \\
\text { conformity to the } \\
\text { taken-for-granted criteria, } \\
\text { norms and beliefs }\end{array}$ \\
\hline Environment & technical & ecological & institutional \\
\hline $\begin{array}{l}\text { A move } \\
\text { towards } \\
\text { isomor- } \\
\text { phism at the } \\
\text { macro level }\end{array}$ & $\begin{array}{l}\text { "isomorphism occurs because } \\
\text { increased environmental } \\
\text { differentiation has to be } \\
\text { matched by similar patterns of } \\
\text { differentiation within the } \\
\text { organization" (Slack and } \\
\text { Hinings 1994:803) }\end{array}$ & $\begin{array}{l}\text { "Organizations may try to } \\
\text { change constantly; but, } \\
\text { after a certain point in the } \\
\text { structuration of an } \\
\text { organizational field, the } \\
\text { aggregate effect of } \\
\text { individual change is to } \\
\text { lessen the extent of } \\
\text { diversity within the field" } \\
\text { (DiMaggio and Powell } \\
\text { 1983:149) }\end{array}$ & $\begin{array}{l}\text { "By filtering out unfit } \\
\text { members of the } \\
\text { population and favoring } \\
\text { only that subset of } \\
\text { organizations optimally } \\
\text { adapted to a given } \\
\text { configuration of niche } \\
\text { constraints, natural } \\
\text { selection reduces rather } \\
\text { than increases } \\
\text { organizational diversity" } \\
\text { (Astley 1985:224). }\end{array}$ \\
\hline
\end{tabular}

\section{From Structural Contingency Theory to Population Ecology: Explanations and Assumptions}

Structural contingency theory has dominated research on organizational design and organization-environment relations during the 1960-1970s (Drazin and Van de Ven 1985; Hirsch and Lounsbury 1997; Donaldson 2003, 2005; Greenwood et al. 2008). In a nutshell, contingency theory claims that there is no single organizational structure that is universal and fits all types of organizations (Lawrence and Lorsch 1967). Instead, organizational performance depends on the fit or misfit between the structure and the contingency such as size or technology (Pugh et al. 1969; Donaldson 1987, 1995). Fit is traditionally associated with higher performance in comparison with those organizations that were in misfit and contingency theory established this causal relationship, where fit is the cause and performance is the effect (Donaldson 1995). We can summarize the propositions and explanations of contingency theory in the following list of causal relationships:

1. Organizations exist and perform in the context of wider technical environments that specify demands to which organizations must adapt in order to survive and succeed;

2. Fit and misfit affect performance: those organizations that find and maintain a fit between their structures and contingencies are more successful in terms of performance efficiency that their peers that fail to find their fit;

3. Internal structural organizational changes happen frequently and result in a positive outcome: organizations move out of misfit into a fit again. In some sense, contingency theory depicts change as unproblematic and usually successful endeavor. 
In 1977 institutional theory and population ecology had been offered by Meyer and Rowan and Hannan and Freeman respectively in an attempt to provide a more accurate and realistic explanation of organizational design and behavior. Population ecology had been offered by Hannan and Freeman as an alternative theory of organization-environment relations. Their population approach aimed "to understand the forces that shape the structures of organizations over long time spans" (Hannan and Freeman 1989:i). A key idea of the population ecology evolved around the notion of structural inertia which limits the capacity of organizations to make radical changes in strategy and structure (Freeman and Hannan 1983:1116). As such, population ecology attempted to approach the questions of organizational birth and death and more, specifically, founding and mortality rates at the macro level of analysis (Carroll and Delacroix 1982; Baum and Oliver 1991).

Population ecology challenged and rejected the main assumption in contingency theory, namely, the concept of adaption (Hannan and Freeman 1977, 1989). While contingency theorists assumed that individual adaptation and rational managerial response take place each time when there is a misfit between contingencies and structure in order to regain the fit and improve performance (or survive), population ecologists maintained that instead an adaptive organizational change is a rare phenomenon due to inertial resistance (Hannan and Freeman 1984). Moreover, instead of talking about individual responses, it makes sense to conceptualize adaptation and survival only at the level of the population: organizations and their managers have little or nothing to offer in response when the environment changes significantly so misfitted organizational forms simply disappear as being no longer able to survive. Adaptation occurs again at the level of population, from the newly entering organizations and new, adapted organizations reflect changes in the design of structure; little or no change is possible at the level of individual organization as a direct response to changing environmental demands. Existing organizations fail to respond quickly and adaptively to environmental changes and, contrary to what contingency theory says, do not survive (Donaldson 1995).

Both population and institutional theories had been built on the critics of contingency theory as obsolete and inadequate depiction of organizational adaptation to environmental tasks. These new theories radically revisited and reformulated the very nature of organizations, environments, change, fit, adaptation, forces that influence organizations and methods of analysis. Hannan and Freeman, for instance, explicitly stated that population ecology theory has been developed as an alternative to contingency theory and adaptation perspective. Similarly, Meyer and Rowan raised doubts with regard to almost all assumptions and explanations that contingency theorists had at that time and offer instead alternative radical reorientations and unexpected, counterintuitive explanations and predictions such as isomorphism and decoupling.

\section{Institutional Theory Emerges}

In developing institutional ideas, Meyer and Rowan explicitly acknowledged the central premise of organization theory of the 1970s - a fit between organizations and environments (Kraatz and Zajac 1996; Greenwood et al. 2008). Namely, they start with the then-prevailing program thesis of contingency theory that "organizations are structured by phenomena in their environments and tend to become isomorphic with them" (Meyer and Rowan 1977:346) but take this claim as a starting point for their criticism and depart from the notion of technical environments. Instead, "organizations structurally reflect socially constructed reality" (Meyer and Rowan 1977:346). In this respect, they provide different explanations for organizational 
adaptation to their environments and different ontology of organizational and social reality. Barley (2008:491) notes that institutional theory arrived just in time to challenge the dominant "rational" contingency explanations and to "counterbalance" newly emerged population ecology.

By shifting an emphasis from technical to institutional environments institutional theory postulates that organizations "are deeply and essentially embedded in wider institutional environments" (Scott and Meyer 1994:1) and conforming to these environmental pressures allows organizations to survive and succeed in their environment. According to institutionalists, socially constructed institutional demands are at least equally important for organizational performance and maintenance as efficiency and technical demands do, although Meyer and Rowan in their seminal paper stressed the primary importance of institutional effects: "Organizations that do so [incorporate the practices and procedures defined by prevailing rationalized concepts of organizational work and institutionalized in society] increase their legitimacy and their survival prospects, independent of the immediate efficacy of the acquired practices and procedure" (Meyer and Rowan 1977:340). Over time, organizations that adopt similar practices, structures and strategies become increasingly similar to each other, contributing to the overall homogeneity of the field (Tolbert and Zucker 1983; Deephouse 1996; Boxenbaum and Jonsson 2008). In this point institutional theory shares the same prediction with population ecology regarding the inability or at least strong convergent forces against individual adaptation and divergence from institutionalized settings. ${ }^{12}$

Phenomenological roots of institutional theory allow it to analyze "the causes of institutionalization in organizations and the processes by which organizations acquire social acceptability and endorsement as a consequence of conformity to the norms and expectations of the institutional environment" (Oliver 1992:563). Similar to population ecology, institutional theory emerged as a response to overly rational depictions of organizational decision making and adaptation to technical requirements in contingency theory (Perrow 1985; Barley and Tolbert 1997). More than any other organizational theory, new institutionalism is focused on its distinctive ontology - institutions and institutional effects. Since Meyer and Rowan's paper it was accepted by institutional research program that institutional environments are more important than technical environment and the former has a defining impact on organizations to the extent that the most radical versions of institutional theory see organizations as not simply embedded or constrained by institutions but constructed and derived from institutional building blocks and are nothing but reflections of prevailing institutional logics. Institutionalists in general are so concerned with explaining institutions that at some point in time these constructs even overshadowed organizations as such (Greenwood et al. 2014; Lopdrup-Hjorth 2015; du Gay and Lopdrup-Hjorth 2016; Johnsen 2018; du Gay 2020; Aksom and Tymchenko 2020).

There have been numerous attempts to develop and extend institutional theory (mainly in an attempt to artificially overcome the so-called paradox of embedded agency) but since Meyer and Rowan and DiMaggio and Powell, only few really successful papers emerged. Probably the most innovative and non-trivial attempt to push the boundaries of institutional theory was made by Christine Oliver in her papers on strategic responses (Oliver 1991) and deinstitutionalization (Oliver 1992). Although technical details and consistency with the former institutional explanation can be doubted and debated, in general, she rightly outlines

\footnotetext{
${ }^{12}$ In this respect, both theories have been criticized for marginalizing the role of managers and reducing managerial work to the "imitate-or-die" dichotomy (Hirsch and Lounsbury 1997:80; Donaldson 1995).
} 
the domain of institutionalism and where and how it could be challenged further. But the core ideas remained: the role of institutional environments on conforming behavior and adaptation.

Both institutional theory and population ecology recognize one of the central postulates of the evolutionary theory: Darwin's "survival of the fittest" is really a special case of a more general law of survival of the stable" (Dawkins 1976:15). They however provide different explanations of the reasons for stability. Institutional theory claims that organizations conform to their institutional environments in order to gain stability while ecologists maintain that stability is a feature and virtue of most mature organizations and this stability makes it so difficult and costly to change in response to environmental shifts.

\section{Elements of Contingency Theory Retained through Transition}

\section{Organizational Change and Adaptation}

The world of organizations as depicted by organizational theories of the 1960s and 1970s is the world similar to Darwinian: there are no final and ultimate tasks that organizations had to achieve and organizational changes and developments are not goal-directed at all. Thus, all macro organizational theories stress the vital importance for organizations to encounter and adapt to changes their environments require.

However, population ecology and institutional theory reject the possibility of fast and largely unproblematic individual adaptation to changed contingencies. According to population ecology, those organizations that become incompatible with the environment are eventually replaced through competition with new organizations better suited to external demands. In this case, we consider a natural selection instead of individual adaptation. Adaptation happens in the long-run when organizations with a high risk of failure are more likely to be selected out and the population of surviving organizations (the one that, in fact, is better adapted to current environmental conditions) will persist.

Institutional theory retains two major ideas about the structural relations between organizations and environments that were present in contingency and population theories. First, organizations must adapt to environmental demands whether they are technical (contingency theory) or institutional (new institutionalism). Accordingly, organizational survival and performance improvement depend on the ability to adapt to environmental demands and move out from the misfit. Second, inertia prevents organizations from further fast and divergent changes. In population ecology this inertia makes it almost impossible for individual organizations to adapt and succeed in making radical changes in strategy and structure in the face of environmental threats (Hannan and Freeman 1984:149). In institutional theory this inertia is conceptualized in the same way: the higher the degree of institutionalization in the field the more it is difficult for individual organizations to change or resist institutional demands (DiMaggio and Powell 1983). Here we can see the same structural relations between organizations and their environments: what is different between these two theories in this prediction is only their ontological framing of this relation.

Therefore, both ecologists and institutionalists depict fundamentally different unobservable forces of organizational world, rejecting individual adaptation and introducing instead structural inertia and isomorphic constrains that prevent organizations in mature fields (population) from further changes and deviations (DiMaggio and Powell, 1983; Hannan and Freeman 1984). 
Adaptation remained to be an important structural feature not only in contingency theory but in new theories as well, being able to survive a paradigm shift and not being abandoned entirely. The claim that organizations adapt to environments is present in all three theories but explained within different forces (adaptation, selection and conformity). The difference is mainly in the degree and speed of adaptation and structural change. For institutionalists adaptation means conformity to the taken-for-granted norms and expectations of the institutional environments (while change is non-problematic in this case) while the process of radical change, resistance or escape from mature institutionalized fields are so rare and counterintuitive phenomena that institutional literature either ignores these questions or offer artificial, farfetched and conflicting explanations such as institutional entrepreneurship or institutional work notions. Population ecologists see adaptation as a form of selection that occurs at the level of populations while individual change is unlikely and risky. However, in their 1984 paper Hannan and Freeman shed more light on the nature and frequency of change. They specified that population ecology does not deny the possibility of individual change and argued that organizations "sometimes even manage to make radical changes in strategies and structures" (Hannan and Freeman 1984:149). They saved the same structure of explanation as institutionalists and contingency theorists did (environmental forces influence organizations and force them to respond) but only altered the degree and chance of successful change outcome.

As such, all three theories argue that

1. Organizations adapt to environmental demands in order to succeed and survive;

2. Organizations (population in case of organizational ecology) that fail to conform demonstrate the lower performance or/and fail to survive;

3. There is a diversity of organizational forms but over time (technical/institutional/selection) forces damage and/or remove those organizations that fail to conform and favor those that have adapted and structured themselves in accordance with demands.

It can be seen that all three theories also maintain the transition from diversity to isomorphic tendencies, explaining how over time organizational fields tend to converge towards similarity and organizations tend to become similar to each other.

\section{A Survival of the Fittest}

Each of these three theories can be summarized along the following similar structural features:

1. Organizations exist and depend on their environments;

2. Organizations must conform to the demands of their environments if one aims to survive and succeed and only the fittest organizations do in fact survive and succeed.

It can be concluded that the major structural correspondence between all three theories relates to the "survival of the fittest" principle which has been retained through the transition from contingency theory to population ecology and institutional theory. While each theory makes a distinctive and contradicting conceptualization of what the environment is, the later is an unobservable phenomenon and the most important is how organizations respond to this force (observable effects). The conclusion that organizations conform to these imperatives and aim to fit the environmental demands is what makes organizational theories instrumentally useful and allows linking them as sharing the same understanding of the structural relations of the 
world. The causal link between the environmental pressures, organizational conformity and the survival of the fittest is the structural content of CT, PE and IT theories. All three theories correspond with each other and even despite their conflicting and excluding views on the nature of environments they provide us with the correct description of observable phenomena and the impact of the unobservable phenomenon.

Contingency theory is thus the most useful theory of organizational change and decisionmaking process while institutional theory and population ecology are better equipped and focused on the question about the similarity of structural forms and resistance to change. Furthermore, institutional theory is well developed for the explanations of ideas and practices diffusion. Each theory thus has its distinct domain of application and relevant questions while, at the same time, they are all interconnected and share the same picture of the (organizational) world.

Why this conclusion is so important? Because it frees us from the necessity to accept that if one theory is right than the other one is wrong. Without structural correspondence we would have assumed that population ecology or contingency theory are wrong in the world where institutional theory is correct, adequate and self-consistent description of reality. Otherwise, other theories would not fit the reality of institutionalists and vice versa. There are wellconfirmed relations among phenomena that are shared by all organization-environment theories and these structural relations of the world must be retained by future theories.

\section{Structural, Institutional and Selection Isomorphism}

Another common point evident in each of three theories is a prediction of isomorphism that occurs over time in organizational fields and populations respectively. In the case of contingency theory the isomorphism thesis can be assumed ${ }^{13}$ while in its successors this conclusion directly follows:

"Hannan and Freeman...began their analysis of population ecology with the question: "Why are there so many kinds of organizations?" ...but as a point of departure for population ecology is misleading. Population ecology emphasizes forces that make organizations more uniform rather than more diverse. The theory of natural selection does not explain how new populations multiply to increase organizational variety; instead, it begins with existing populations and explains how differential survival progressively refines and homogenizes organizational forms as it perfects their adaptation to environments" (Astley 1985:224).

Similarly, for institutional theory this conclusion is given in DiMaggio and Powell's paper:

"Once disparate organizations in the same line of business are structured into an actual field (as we shall argue, by competition, the state, or the professions), powerful forces emerge that lead them to become more similar to one another. Organizations may change their goals or develop new practices, and new organizations enter the field. But, in the long run, organizational actors making rational decisions construct around themselves an environment that constrains their ability to change further in later years." (1983:148).

\footnotetext{
${ }^{13}$ Individual and rational organizational change still may lead to isomorphic tendencies at the macro level since technical requirements must be similar within a single environment.
} 
Finally, in contingency theory:

"Formal organizations become matched with their environments by technical and exchange interdependencies" (Meyer and Rowan 1977346).

Both quotes above provide a causal-relationship structure of population ecology and new institutionalism with regard to the shift from diversity to isomorphism. We can perceive this thesis as an extension of contingency theory arguments that follows logically from the former theory or as a special case of more broad explanations provided by the new institutionalism and population ecology.

\section{The Existence and Nature of Forces in Organizational Theories}

In fact, what organizational theories recognize and describe are forces. Forces constitute the cornerstone of most scientific theories and laws of nature. Although hidden from direct observation and despite the fact that "we have no clear conception of what they are" (Bigelow et al. 1988:614), we can establish the effect they product and the way observable reality changes under the influence of forces. This conceptualization of forces echoes structural realist's epistemology of unobservables and relation between objects: "[structural relations] teach us that there is such and such a relation between this thing and some other thing; only this something formerly we called motion; we now call it electric current. But these appellations were only images substituted for the real objects which Nature will eternally hide from us" (Poincaré 1905/2001: 140-141). By connecting these two streams of philosophy of science we can conclude that forces are what we can be able to recognize and describe despite our inability to understand their nature. Forces are what all organizational theories recognize but imagine in different ways. Scientific theories, according to structural realism can at best "reveal relations between objects" (Psilos 1995:21), that is, postulate that a kind of force exists and produces the effects that we, in turn, capture and explain the facts that caused them. Here a third stream of philosophical literature, namely, Constructive Empiricism claims that science doesn't aim to have (neither it can) a true theories about unobservables but only empirically adequate descriptions, explanations and predictions of observable phenomena (van Fraassen 1980; Rosen 1994; Maher 1990). In some sense, these three positions claim the same characteristics and limits of scientific theories: we can only trust and accept what empirically successful (adequate) theories tell about the observable phenomena and the structural relations between phenomena and should not expect that theories will correctly describe the nature of unobservable aspects of the world that cause the phenomena. It is the more epistemically pessimistic position that scientific realism but it allows solving such inconsistency as the incommensurability between various coexisting theories by rejecting their ontological claims and to indicate the mark of progress which consists of the presence of structural correspondence between theories - a common ground they share by claiming the same kind of forces.

Hunt and Suchting (1969) together with Ellis (1976) provide the following distinguishing characteristics of the force:

1) “...in some sense their existence entails and is entailed by the existence of the effects they are supposed to produce" (31);

2) "a system is acted upon by a force (or forces) if and only if...the system persists in an unnatural state or...is changing in an unnatural way" (45). 
Organizational theories we analyze in this paper had been developed in order to recognize, establish and predict the existence of forces and the way organizations respond to them. Contingency theory, new institutionalism and population ecology claim the existence of (technical/institutional/ecological) environments and the misfit organizations experience when they resist or ignore environmental demands. In institutional theory, the trend towards conformity and isomorphism is an example of such a disturbance of the system (organization) and the change in an unnatural way. Similarly, population ecology postulates that selection is a kind of force that chooses the most suitable organizations and to which influence organizations attempt to adapt.

Contingency theory which laid the foundation of the description of environmental forces that influence organizations postulated that organizations move from fit into misfit and back again in response to changed contingencies.

Organizational response is predicted by the environmental conditions, be they technical, ecological or institutional. The difference is only in the ability to successfully move from the misfit to fit again and in the nature of change.

Donaldson described the causal relations between the forces that affect organizations and how organizations react to this disturbance of the system and try to return back into equilibrium:

"Organization initially in fit, then increase in contingency variable produces misfit and reduces performance, and then structure is changed adaptively from misfit to a new fit which restores equilibrium" (Donaldson 1995:33).

Forces, the impact they produce on organizations and organizational responses to forces are a common point that all organizational theories share (Thompson 1967; Meyer and Rowan 1977; Hannan and Freeman 1977, 1984; DiMaggio and Powell 1983; Oliver 1991; Donaldson 1995). Each theory offers a unique, distinctive and competing view on the nature of the force but they put forward incompatible ontology: otherwise, we need to choose which theory is wrong and which one doesn't adequately fit into empirical reality (Weinert 1994). All theories nevertheless can be reduced to the structure and causal relationship between the force and the effect it produces.

\section{Maintaining the Logic of Multiple Theories Coexistence}

A former correspondence principle developed by Niels Bohr aimed at defending the cumulative nature of science and continuity in theory change and surviving of theories. For example, one should talk about quantum theory as a rational generalization of classical mechanics. Bohr saw continuity between old and new theories and maintained that classical mechanics has not been replaced but rather survived the quantum revolution in a new form (Bokulich and Bokulich 2005:349). Fritz Rohrlich (1989) extended this framework beyond theory change and argued that regardless of whether there are theory change dynamics, there must be a correspondence between all currently existing theories even though they claim different and incompatible ontologies.

The latest correspondence applies also to our case of different coexisting organizational theories (Donaldson 1995; McKinley et al. 1999; Aksom 2021). A growing pluralism of contradicting theories is said to lead to ever-increasing fragmentation and incommensurability if using a scientific realist understanding of the field. In order to ensure the progress in the 
field, theories should depart from each other as little as possible and this isomorphism is recognized in the form of structure retention. While structural relations between phenomena is all we can know this level is still enough for concluding that contingency theory, new institutionalism and population ecology share the same view on the logical features of organization-environment world.

\section{Conclusion}

In this paper we raised the question of whether there is a correspondence between coexisting organization-environment theories and whether there is progress in the form of cumulative shift. A traditional concept of scientific progress is depicted in the form of verisimilitude through the falsification and abandonment of false theories in favor of those that demonstrate their superiority over competitors and thus survive (Popper 1963; Niiniluoto 1987, 2015). In this case we may ask whether a new theory retains some successful aspects of its predecessor and thus gets closer to the truth or it is merely a change, not progress: false theories are abandoned in favor of another false theory that, in turn, over time will be replaced within another new false theory (Laudan 1981; Niiniluoto 2015). The progress here is illustrated usually within an example of Newtonian mechanics as a special case of quantum physics because the latter reproduces classical physics in the limit of large quantum numbers. However, there is another course of development that takes place in many sciences and research fields including organization theory and organizational research. Here, many theories coexist relatively peacefully serving merely as a toolkit for instruments rather than being a battlefield where different incommensurable theories compete head to head for survival. There are also several examples where theories coexist as a repertoire of different theoretical frameworks but there is a question of whether we can accept them as describing the same reality. Examples again come from the field of physics (general relativity vs. quantum mechanics) and from organization studies (different theories of organization-environment relations). In the latest field, the incommensurability takes place at the level of unobservable theoretical terms. The correspondence principle here is best understood in terms of structural correspondence, that is, structural relations between unobservables and observables and, at best, theories reveal the logical form or structure of the underlying organizational (social, physiological or economical) reality regardless of the difference in ontological claims.

According to both scientific realism and antirealism one cannot tell whether each of alternative theories of organization-environment relations is either true or false or whether any of them contributes to increasing understanding or adds true knowledge. In other words, any theory can be found false. Structural realism, in contrast, allows recognizing the common structural correspondence that unifies these divergent theories and marks a common core knowledge that all theories acknowledge and share. While these theories postulate different, incommensurable unobservable phenomena they nevertheless share a common conclusion with regard to the nature of relations between observable and unobservable phenomena. Scientific progress thus is present in a form of correspondence and unification between different theories. The latest is the most progressive form of different theories' reconciliation.

Our study concludes with a proposition to treat organizational theories in an instrumentalist manner. We don't have reasons to believe in unobservable phenomena these theories postulate but we can accept 1) what they say about observables and 2) about the structure between observables and unobservables (van Fraassen 1980; Worrall 1989). We argue, therefore, that the philosophy of 
organizational research departs from scientific realism and instead drifts towards more pessimistic philosophies. In line with structural realism we maintain that organizational theories correctly describe the structure, not the nature of postulated phenomena. In line with the philosophy of constructive empiricism one can accept a minimal requirement for organizational research: to empirically adequate theories, that is, those theories, that do not deny the existence of unobservables but fulfill their major task, namely, instrumental usefulness in explaining and predicting observable phenomena. Respectively, acceptance of a theory involves as a belief only that it is empirically adequate. We accept organization theories as those that 1) structurally describe the same reality and thus 2) can be justified as empirically adequate without additional metaphysical beliefs in what these theories claim about the nature of unobservables.

Finally, we conclude with defining and defending the presence and the nature of scientific progress in the field of organizational studies as continuity at the level of structural relations between alternative theories, not at the level of their ontology which would have been too optimistic view. At the same time, our definition of progress is more optimistic than, for example, one of Kuhnian interpretation, namely, that there is no progressive retainment, communication and correspondence between different theories.

Funding Open Access funding provided by University of Jyväskylä (JYU).

Open Access This article is licensed under a Creative Commons Attribution 4.0 International License, which permits use, sharing, adaptation, distribution and reproduction in any medium or format, as long as you give appropriate credit to the original author(s) and the source, provide a link to the Creative Commons licence, and indicate if changes were made. The images or other third party material in this article are included in the article's Creative Commons licence, unless indicated otherwise in a credit line to the material. If material is not included in the article's Creative Commons licence and your intended use is not permitted by statutory regulation or exceeds the permitted use, you will need to obtain permission directly from the copyright holder. To view a copy of this licence, visit http://creativecommons.org/licenses/by/4.0/.

\section{References}

Achinstein, P. 1963. Theoretical terms and partial interpretation. The British Journal for the Philosophy of Science 14 (54): 89-105.

Achinstein, P. 2000. Observation and theory. In A companion to the philosophy of science, ed. W.H. NewtonSmith, 325-334. Oxford: Blackwell.

Achinstein, P. 2002. Is there a valid experimental argument for scientific realism? Journal of Philosophy 99 (9): $470-495$.

Aksom, H. (2020), Rethinking deinstitutionalization: Exploring the boundary conditions for abandoning and decoupling highly diffused and institutionalized practices. Preprint.

Aksom, H. (2021). Reconciling conflicting predictions about transience and persistence of management concepts in management fashion theory and new institutionalism. International Journal of Organizational Analysis, forthcoming.

Aksom, H., and I. Tymchenko. 2020. How institutional theories explain and fail to explain organizations. Journal of Organizational Change Management 33 (7): 1223-1252.

Aksom, H., O. Zhylinska, and T. Gaidai. 2020. Can institutional theory be refuted, replaced or modified? International Journal of Organizational Analysis 28 (1): 135-159.

Astley, W. G. (1985). The two ecologies: Population and community perspectives on organizational evolution. Administrative Science Quarterly, 224-241.

Ayala, F.J. 1968. Biology as an autonomous science. American Scientist 56 (3): 207-221.

Barley, S.R. 2008. Coalface institutionalism. In The Sage handbook of organizational institutionalism, ed. R. Greenwood, C. Oliver, K. Sahlin, and R. Suddaby, 822. London: Sage. 
Barley, S.R., and P.S. Tolbert. 1997. Institutionalization and structuration: Studying the links between action and institution. Organization Studies 18 (1): 93-117.

Baum, J.A., and C. Oliver. 1991. Institutional linkages and organizational mortality. Administrative Science Quarterly 36 (2): 187-218.

Bigelow, J., B. Ellis, and R. Pargetter. 1988. Forces. Philosophy of Science 55 (4): 614-630.

Bird, A. 2007. What is scientific progress? Nô̂s 41 (1): 64-89.

Bogen, J. 2011. 'Saving the phenomena'and saving the phenomena. Synthese 182 (1): 7-22.

Bogen, J., and J. Woodward. 1988. Saving the phenomena. The Philosophical Review 97 (3): 303-352.

Böhme, G. 1980. On the possibility of 'closed theories'. Studies in History and Philosophy of Science Part A 11 (2): 163-172.

Bokulich, P., and A. Bokulich. 2005. Niels Bohr's generalization of classical mechanics. Foundations of Physics 35 (3): 347-371.

Boxenbaum, E., and S. Jonsson. 2008. Isomorphism, diffusion and decoupling. In, ed. R. Greenwood, C. Oliver, R. Suddaby, and K. Sahlin-Andersson, 78-98. Thousand Oaks, CA: Sage.

Brush, S. 1968. Mach and atomism. Synthese 18 (1): 192-215.

Bunge, M. 1973. Philosophy of physics. Dordrecht: Reidel.

Burrell, G., and G. Morgan. 1979. Sociological paradigms and organizational analysis. London: Heinemann.

Cao, T.Y. 2003. Structural realism and the interpretation of quantum field theory. Synthese 136 (1): 3-24.

Cao, T.Y. 2019. Conceptual development of 20th century field theories. Cambridge: Cambridge University Press.

Carrier, M. 1991. What is wrong with the miracle argument?? Studies in History and Philosophy of Science Part A 22 (1): 23-36.

Carroll, G.R., and J. Delacroix. 1982. Organisational mortality in the newspaper industries of Argentina and Ireland: an ecological approach. Administrative Science Quarterly 21 (2): 169-198.

Cevolani, G., and L. Tambolo. 2013. Progress as approximation to the truth: A defence of the verisimilitudinarian approach. Erkenntnis 78 (4): 921-935.

Chakravartty, A. 2003. The structuralist conception of objects. Philosophy of Science 70 (5): 867-878.

Chakravartty, A. 2004. Structuralism as a form of scientific realism. International Studies in the Philosophy of Science 18 (2-3): 151-171.

Chakravartty, A. 2007. A metaphysics for scientific realism: Knowing the unobservable. Cambridge: Cambridge University Press.

Davis, G.F. 2010. Do theories of organizations progress? Organizational Research Methods 13 (4): 690-709.

Davis, G.F. 2015. Celebrating organization theory: The after-party. Journal of Management Studies 52 (2): 309-319.

Davis, G.F., and W.W. Powell. 1992. Organization-environment relations. In Handbook of industrial and organizational psychology, ed. M.D. Dunette and L.M. Hough, 315-376. Palo Alto, CA: Consulting Psychologists Press.

Dawid, R. 2013. String theory and the scientific method. Cambridge: Cambridge University Press.

Dawid, R. 2019. The significance of non-empirical confirmation in fundamental physics. In Why trust a theory?-Reconsidering scientific methodology in light of modern physics, ed. R. Dardashti, R. Dawid, and K. Thebault. Cambridge: Cambridge University Press.

Dawkins, R. 1976. The selfish Gene. Oxford: Oxford University Press.

de Ronde, C. 2018. Quantum superpositions and the representation of physical reality beyond measurement outcomes and mathematical structures. Foundations of Science 23 (4): 621-648.

Deephouse, D.L. 1996. Does isomorphism legitimate? Academy of Management Journal 39 (4): 1024-1039.

Dellsén, F. 2016. Scientific progress: Knowledge versus understanding. Studies in History and Philosophy of Science Part A 56: 72-83.

DiMaggio, P., and W. Powell. 1983. The iron cage revisited: Institutional isomorphism and collective rationality in organizational fields. American Sociological Review 48 (2): 147-160.

Dobbin, F., and C.B. Schoonhoven. 2010. An organizational sociology of Stanford's organization theory renaissance. In Stanford's organization theory renaissance, 1970-2000. Research in the sociology of organizations (Vol. 28), ed. F. Dobbin and C.B. Schoonhoven. Bingley: Emerald Publishing.

Donaldson, L. 1987. Strategy and structural adjustment to regain fit and performance: In defence of contingency theory. Journal of Management Studies 24 (1): 1-24.

Donaldson, L. 1995. American anti-management theories of organization: A critique of paradigm proliferation. Cambridge: Cambridge University Press.

Donaldson, L. 2003. Organization theory as a positive science. In The Oxford handbook of organization theory, ed. H. Tsoukas and C. Knudsen, 39-62. Oxford: Oxford University Press.

Donaldson, L. 2005. Vita contemplativa: Following the scientific method: How I became a committed functionalist and positivist. Organization Studies 26 (7): 1071-1088.

Doppelt, G. 2005. Empirical success or explanatory success: What does current scientific realism need to explain? Philosophy of Science 72 (5): 1076-1087. 
Drazin, R., and A.H. Van de Ven. 1985. Alternative forms of fit in contingency theory. Administrative Science Quarterly 30 (4): 514-539.

du Gay, P. (2020). Disappearing 'formal organization': How organization studies dissolved its 'core object', and what follows from this. Current Sociology, forthcoming.

du Gay, P. 2020. Disappearing 'formal organization': How organization studies dissolved its 'core object', and what follows from this. Current Sociology 68 (4): 459-479.

Dyson, F.J. 1964. Mathematics in the physical sciences. Scientific American 211 (3): 128-147.

Einstein, A. 1934. On the method of theoretical physics. Philosophy of Science 1 (2): 163-169.

Ellis, B. 1976. The existence of forces. Studies in History and Philosophy of Science Part A 7 (2): 171-185.

Ellis, G., and J. Silk. 2014. Scientific method: Defend the integrity of physics. Nature 516 (7531): 321-323.

Engler, G. 2002. Einstein and the most beautiful theories in physics. International Studies in the Philosophy of Science 16 (1): 27-37.

Feyerabend, P. 2010. Against method, 4th ed. London: Verso.

Firsova, S., T. Bilorus, and H. Aksom. 2020. Closed theories, Falsificationism and non-cumulative Progress. Problemos 98: 125-135.

Freedman, D.Z., and P. Van Nieuwenhuizen. 1978. Supergravity and the unification of the laws of physics. Scientific American 238 (2): 126-143.

Freeman, J., and M.T. Hannan. 1983. Niche width and the dynamics of organizational populations. American Journal of Sociology 88 (6): 1116-1145.

Gödel, K. 1949. An example of a new type of cosmological solutions of Einstein's field equations of gravitation. Reviews of Modern Physics 21 (3): 447.

Godfrey, P.C., and C.W. Hill. 1995. The problem of unobservables in strategic management research. Strategic Management Journal 16 (7): 519-533.

Greenwood, R., C. Oliver, K. Sahlin-Andersson, and R. Suddaby. 2008. The SAGE handbook of organizational institutionalism. London: SAGE Publications.

Greenwood, R., C.R. Hinings, and D. Whetten. 2014. Rethinking institutions and organizations. Journal of Management Studies 51 (7): 1206-1220.

Hambrick, D.C. 2007. The field of management's devotion to theory: Too much of a good thing? Academy of Management Journal 50 (6): 1346-1352.

Hannan, M.T., and J. Freeman. 1977. The population ecology of organizations. American Journal of Sociology 82 (5): 929-964.

Hannan, M.T., and J. Freeman. 1984. Structural inertia and organizational change. American Sociological Review: 149-164.

Hannan, M.T., and J. Freeman. 1989. Organizational ecology. Cambridge, MA: Harvard University Press.

Heisenberg, W. 1987. Steps beyond the horizon. Moscow: Progress.

Hirsch, P.M., and M. Lounsbury. 1997. Putting the organization back into organization theory: Action, change, and the" new" institutionalism. Journal of Management Inquiry 6 (1): 79-88.

Hooker, C.A. 1975. On global theories. Philosophy of Science 42 (2): 152-179.

Hunt, I.E., and W.A. Suchting. 1969. Force and“ natural motion”. Philosophy of Science 36 (3): 233-251.

Jarvie, I.C. 1979. Review symposium: Laudan's problematic progress and the social sciences. Philosophy of the Social Sciences 9 (4): 484497.

Johnsen, C.G. 2018. Who's afraid of organization? Concepts, process and identity thinking. Philosophy of Management 17 (3): 303-319.

Jones, R. 1991. Realism about what? Philosophy of Science 58 (2): 185-202.

Kapp, R.O. 1958. Ockam's razor and the unification of physical science. The British Journal for the Philosophy of Science 8 (32): 265-280.

Kitcher, P. 1978. Theories, theorists and theoretical change. The Philosophical Review 87 (4): 519-547.

Kraatz, M.S., and E.J. Zajac. 1996. Exploring the limits of the new institutionalism: The causes and consequences of illegitimate organizational change. American Sociological Review: 812-836.

Krajewski, W. 1977. Correspondence principle and growth of science. Dordrecht: Reidel.

Kuhn, T. 1970. The structure of scientific revolutions (2nd ed.). Chicago: The University of Chicago Press.

Ladyman, J. 1998. What is structural realism? Studies in History and Philosophy of Science 29A (3): 409-424.

Ladyman, J. 2011. Structural realism versus standard scientific realism: The case of phlogiston and dephlogisticated air. Synthese 180 (2): 87-101.

Ladyman, J. 2018. Scientific realism again. Spontaneous Generations: A Journal for the History and Philosophy of Science 9 (1): 99-107.

Lakatos, I. 1970. Falsification and the methodology of scientific research programmes. In Criticism and the growth of knowledge, ed. I. Lakatos and A. Musgrave. London: Cambridge University Press.

Lakatos, I. 1974. The role of crucial experiments in science. Studies In History and Philosophy of Science Part A 4 (4): 309-325. 
Laudan, L. 1981. A confutation of convergent realism. Philosophy of Science 48 (1): 19-49.

Laudan, L. 1984. Realism without the real. Philosophy of Science 51 (1): 156-162.

Laudan, L., A. Donovan, R. Laudan, P. Barker, H. Brown, J. Leplin, et al. 1986. Scientific change: Philosophical models and historical research. Synthese 69 (2): 141-223.

Lawrence, P.R., and J.W. Lorsch. 1967. Organization and environment: Managing differentiation and integration. Boston, MA: Harvard University Press.

Lesher, J.H. 1978. On the role of guesswork in science. Studies in History and Philosophy of Science Part A 9 (1): 19-33.

Levinthal, D.A., and L. Marengo. 2020. Organizations, ambiguity, and conflict: Introduction to the special issue in honor of James G. March. Industrial and Corporate Change 29 (1): 81-87.

Lopdrup-Hjorth, T. 2015. Object and objective lost? Organization-phobia in organization theory. Journal of Cultural Economy 8 (4): 439-461.

Madsen, D.Ø., and K. Slåtten. 2015. The balanced scorecard: Fashion or virus? Administrative Sciences 5 (2): 90-124.

Maher, P. 1990. Why scientists gather evidence. The British Journal for the Philosophy of Science 41 (1): 103-119.

Mamchur, E. 1987. The heuristic role of aesthetics in science. International Studies in the Philosophy of Science 1 (2): 209-222.

Mamchur, E. 2017. Unobservable entities in modern physics: Social constructs or real objects? Epistemology \& Philosophy of Science 51 (1): 106-123.

March, J., and H.A. Simon. 1958. Organizations. New York: Wiley.

Massimi, M. 2007. Saving unobservable phenomena. The British Journal for the Philosophy of Science 58 (2): 235-262.

Maxwell, N. 1972. A critique of Popper's views on scientific method. Philosophy of Science 39 (2): 131-152.

McKinley, W., M.A. Mone, and G. Moon. 1999. Determinants and development of schools in organization theory. Academy of Management Review 24 (4): 634-648.

Meyer, J.W., and B. Rowan. 1977. Institutionalized organizations: Formal structure as myth and ceremony. American Journal of Sociology 83 (2): 340-363.

Moberg, D.W. 1979. Are there rival, incommensurable theories? Philosophy of Science 46 (2): 244-262.

Monton, B. and Mohler, C. (2012) Constructive empiricism, in E. N. Zalta (ed.), the Stanford encyclopedia of philosophy (winter 2012 edition), http://plato.stanford.edu/ entries/constructive-empiricism/.

Musgrave, A.E. 1973. Falsification and its Critics. Studies in Logic and the Foundations of Mathematics 74 (1): 393-406.

Musgrave, A. 1988. The ultimate argument for scientific realism. In Relativism and realism in science, ed. R. Nola, 229-252. Dordrecht: Kluwer.

Niiniluoto, I. 1984. Is science progressive? Dordrecht: D. Reidel.

Niiniluoto, I. 1987. Truthlikeness. Dordrecht: D. Reidel.

Niiniluoto, I. (2015). Scientific progress. In E. Zalta (ed.), the Stanford encyclopedia of philosophy, http:// plato. stanford.edu.

Niiniluoto, I. 2020. Truthlikeness: Old and new debates. Synthese 197 (4): 1581-1599.

Nugayev, R. 1985. A study of theory unification. The British Journal for the Philosophy of Science 36 (2): 159-173.

Nugayev, R.M. 2015. Communicative rationality of the Maxwellian revolution. Foundations of Science 20 (4): 447-478.

Oliver, C. 1991. Strategic responses to institutional processes. Academy of Management Review 16 (1): $145-179$.

Oliver, C. 1992. The antecedents of deinstitutionalization. Organization Studies 13 (4): 563-588.

Papineau, D. 1996. The philosophy of science. Oxford: Oxford University Press.

Park, S. 2011. A confutation of the pessimistic induction. Journal for General Philosophy of Science 42 (1): 75-84.

Park, S. 2017. Does scientific progress consist in increasing knowledge or understanding? Journal for General Philosophy of Science 48 (4): 569-579.

Perrow, C. 1985. Review essay: Overboard with myth and symbols. American Journal of Sociology 91 (1): 151-155.

Perrow, C. 1991. A society of organizations. Theory and Society 20 (6): 725-762.

Pfeffer, J. 1993. Barriers to the advance of organizational science: Paradigm development as a dependent variable. Academy of Management Review 18 (4): 599-620.

Poincaré, H. 1905/2001. Science and hypothesis. In The value of science: Essential writings of Poincaré, ed. S.J. Gould. New York: The Modern Library.

Popper, K.R. 1959. The logic of scientific discovery. New York: Basic Books.

Popper, K. 1962. Some comments on truth and the growth of knowledge. In Logic, methodology and philosophy of science, ed. E. Nagel, P. Suppes, and A. Tarski. Stanford: Stanford University Press.

Popper, K.R. 1963. Conjectures and refutations: The growth of scientific knowledge. London: Hutchinson.

Post, H.R. 1960. Simplicity in scientific theories. The British Journal for the Philosophy of Science 11 (41): 32-41.

Post, H.R. 1971. Correspondence, invariance and heuristics: In praise of conservative induction. Studies in History and Philosophy of Science Part A 2 (3): 213-255.

Psillos, S. 1999. Scientific realism: How science tracks truth. London: Routledge. 
Psillos, S. 2001. Is structural realism possible? Philosophy of Science 68 (S3): S13-S24.

Psillos, S. 2006. The structure, the whole structure, and nothing but the structure? Philosophy of Science 73 (5): 560-570.

Psillos, S. 2011. Choosing the realist framework. Synthese 180 (2): 301-316.

Psilos, S. 1995. Is structural realism the best of both worlds? Dialectica 49 (1): 15-46.

Pugh, D.S., D.J. Hickson, C.R. Hinings, and C. Turner. 1969. The context of organizational structures. Administrative Science Quarterly 14: 91-114.

Putnam, H. 1974. The 'corroboration' of theories. In The philosophy of Karl Popper, ed. P.A. Schilpp, 221-240. LaSalle, IL: Open Court Publishing.

Putnam, H. 1981. Reason, truth, and history. Cambridge: Cambridge University Press.

Rabetino, R., M. Kohtamäki, and J.S. Federico. 2020. A (re) view of the philosophical foundations of strategic management. Forthcoming: International Journal of Management Reviews.

Radder, H. 1991. Heuristics and the generalized correspondence principle. The British Journal for the Philosophy of Science 42 (2): 195-226.

Rohrlich, F. 1988. Pluralistic ontology and theory reduction in the physical sciences. The British Journal for the Philosophy of Science 39 (3): 295-312.

Rohrlich, F. 1989. The logic of reduction: The case of gravitation. Foundations of Physics 19 (10): 1151-1170.

Rohrlich, F. 1990. There is good physics in theory reduction. Foundations of Physics 20 (11): 1399-1412.

Rohrlich, F. 1996. Scientific realism: A challenge to physicists. Foundations of Physics 26 (4): 443-451.

Rolin, K. 2011. Diversity and dissent in the social sciences: The case of organization studies. Philosophy of the Social Sciences 41 (4): 470-494.

Rosen, G. 1994. What is constructive empiricism? Philosophical Studies 74 (2): 143-178.

Røvik, K.A. 2011. From fashion to virus: An alternative theory of organizations' handling of management ideas. Organization Studies 32 (5): 631-653.

Saatsi, J. 2005. Reconsidering the Fresnel-Maxwell theory shift: How the realist can have her cake and EAT it too. Studies in History and Philosophy of Science Part A 36 (3): 509-538.

Sandberg, J., \& Alvesson, M. (2020) Meanings of theory: Clarifying theory through typification. Journal of Management Studies. Forthcoming.

Scherer, A.G. 2003. Modes of explanation in organization theory. In The Oxford handbook of organization theory, ed. H. Tsoukas and C. Knudsen, 310-344. Oxford: Oxford University Press.

Scherer, A.G., and H. Steinmann. 1999. Some remarks on the problem of incommensurability in organization studies. Organization Studies 20 (3): 519-544.

Scott, W.R. 1981. Developments in organization theory, 1960-1980. American Behavioral Scientist 24 (3): $407-$ 422.

Scott, W.R., and J.W. Meyer. 1994. Institutional environments and organizations. Thousand Oaks, CA: Sage.

Slack, T., and B. Hinings. 1994. Institutional pressures and isomorphic change: An empirical test. Organization Studies 15 (6): 803-827.

Small, A.W. 1897. The sociologists' point of view. American Journal of Sociology 3 (2): 145-170.

Smolin, L. 2006. The trouble with physics: The rise of string theory, the fall of a science, and what comes next. Boston: Houghton Mifflin.

Suddaby, R., C. Hardy, and Q.N. Huy. 2011. Where are the new theories of organization? Academy of Management Review 36 (2): 236-246.

Tambolo, L. 2015. A tale of three theories: Feyerabend and Popper on progress and the aim of science. Studies in History and Philosophy of Science Part A 51: 33-41.

Thompson, J.D. 1967. Organizations in action. New York: McGraw-Hill.

Thorne, K.S. 1991. Do the Laws of physics permit closed Timelike curves? Annals of the New York Academy of Sciences 631 (1): 182-193.

Tolbert, P.S., and L.G. Zucker. 1983. Institutional sources of change in the formal structure of organizations: The diffusion of civil service reform, 1880-1935. Administrative Science Quarterly 28 (1): 22-39.

Van De Ven, A.H. 1999. The buzzing, blooming, confusing world of organization and management theory: A view from Lake Wobegon University. Journal of Management Inquiry 8 (2): 118-125.

Van Fraassen, B.C. 1977. To save the phenomena. The Journal of Philosophy 73 (18): 623-632.

van Fraassen, B. 1980. The scientific image. Oxford: Oxford University Press.

van Fraassen, B. 1993. Armstrong, Cartwright, and Earman on laws and symmetry. Philosophy and Phenomenological Research 53 (2): 431-444.

Weick, K.E. 2016. 60th anniversary essay: Constrained comprehending: The experience of organizational inquiry. Administrative Science Quarterly 61 (3): 333-346.

Weinberg, S. 1994. Dreams of a final theory, chapter VII. New York: Vintage.

Weinert, F. 1994. The correspondence principle and the closure of theories: Two incompatible aspects of Heisenberg's philosophy of science. Erkenntnis: 303-323.

Willmott, H. 1993. Breaking the paradigm mentality. Organization Studies 14: 681-719. 
Worrall, J. 1982. Scientific realism and scientific change. The Philosophical Quarterly 32 (128): 201-231. Worrall, J. 1989. Structural realism: The best of both worlds? Dialectica 43 (1-2): 99-124.

Wray, K.B. 2013. Success and truth in the realism/anti-realism debate. Synthese 190 (9): 1719-1729.

Wray, K.B. 2015. Pessimistic inductions: Four varieties. International Studies in the Philosophy of Science 29 (1): $61-73$

Wray, K.B. 2019. Discarded theories: The role of changing interests. Synthese 196 (2): 553-569.

Zel'dovich, Y.B. 1977. Hydrodynamics of the universe. Annual Review of Fluid Mechanics 9 (1): 215-228.

Publisher's Note Springer Nature remains neutral with regard to jurisdictional claims in published maps and institutional affiliations.

Herman Aksom is a researcher at the Department of Accounting, University of Jyväskylä, Finland. His primary research interests are in the areas of organizational institutionalism, accounting and organizational change, organization theory, diffusion of management innovations and philosophy of science. 